\title{
Detection of Left Atrial Myxoma by Radionuclide Cardiac Imaging
}

\author{
A Case Report \\ Tamotsu Osawa, M.D. \\ Department of Radiology, Ken-seibu Hamamatsu Medical Center Hospital \\ Kazutoshi Hirose, M. D. \\ Department of Radiology, Ken-seibu Hamamatsu Medical Center Hospital \\ Satoshi Sawada, M. D. \\ Department of Radiology, Kansai Medical University \\ Hiroshi Hamada, M. D. \\ Department of Radiology, Higashiosaka Shiritsu Chuo Hospital
}

\begin{abstract}
Primary cardiac neoplasms are extremely rare. Recently, it was noted in several reports that the radionuclide angiocardiography was particularly evaluated for the diagnosis of intracardiac tumors. In this paper, a case of left atrial myxoma diagnosed by the radionulide angiocardiography was presented, which was surgically treated with success.
\end{abstract}

\section{INTRODUCTION}

Primary cardiac neoplasms have rarely been found, only in $0.0017-0.03 \%$ among unselected autopsy cases ${ }^{1 / 2)}$. The first case of left atrial myxoma detected with the scintiphotographic examination was reported by Kriss et $\mathrm{al}^{3)}$. Since then, Zaret, B. L. et al 4) described the use of radionuclide angiocardiography and ECG-gated scintiphotographic cardiac imaging and Pohost, G. M. et $\mathrm{al}^{5)}$ recognized on the gated radionuclide cardiac blood pool scans.

In this paper, the authors present a case of left atrial myxoma, of which in the diagnosis the radionuclide angiocardiography and cardiac pool scan played an important role. In this point of view, the significance of scintiphotography for diagnosis of cardiac tumors will be discussed, revewing the references of cardiac tumors detected by scintiphotographic manifestations.

\section{CASE REPORT}

A 55-year-old man having no history of rheumatic disease previously, was admitted 
to the Kenseibu Hamamatsu Medical Center Hospital (KHMCH) on July 10, 1976.

He had been in good health until dyspnea appeared by physical excercise on February, 1976. As dyspnea had increased gradually, the patient admitted to a private hospital under the diagnosis of congestive heart failure due to primary myocardial disease but the pharmacomedical treatment was of little benefit. Then he was referred to the cardiac department of $\mathrm{KHMCH}$ for the purpose of precise examination for cardiac murmur and abnormal electrocardiogram.

Past history was noncontributory, history of diabetes mellitus and hypertention were known in his family.

Physical examination revealed that he was a moderately developed old man having blood pressure of $100 / 70 \mathrm{~mm} H \mathrm{~g}$ and regular pulse rate at $66 / \mathrm{min}$.

Distended juglar veins and moderately enlarged liver without ascites were noted, and there was no ankle edema. Auscultation at the apex revealed a loud first sound and soft systolic murmur. An opening snap was present after the second sound and was followed by a short mid-diastolic murmur. The chest was clear to auscultaion.

Laboratory examinations showed a red blood cell count of 4.59 million and white blood cell count of 8,600 per cubic millimeter, with a hematocrit of 43.1 per cent and a hemoglobin content of $15.0 \mathrm{~g}$ per $100 \mathrm{ml}$ of blood. Blood sedimentation rate was $12 \mathrm{~mm}$ per hour.

Liver funtion tests, serum electrolytes and enzymes, including GOT, GPT, LDH and CPK, were all within normal limits.

The chest roentgenogram revealed slight cardiomegaly with prominence of the pulmonary arteries and veins. Lung fields were almost normal except septal lines in the left basal field (Fig. 1).

The electrocardiogram demonstrated normal sinus rhythm, left atrial enlargement, counter-clockwise rotation, suggesting right ventricular hypertrophy, and non-specific ST-T changes. The echocardiogram showed a large clouds of wavy-lined echoes seen posterior to the anterior leaflet of the mitral valve in the left ventricle during diastole and left atrium during ventricular systole.

The phonocardiogram showed prolonged interval between $Q$ wave and the first sound, loud accentuation of the first sound, and diastolic rumbling with click "tumor plop". The apexcardiogram revealed downward retraction during systole and outward movement corresponding to the tumor plop sound during diastole.

Following the intravenous bolus injection of ${ }^{99 \mathrm{~m}} \mathrm{Tc}$ human serum albumin ${ }^{\left({ }^{9} \mathrm{~m}\right.} \mathrm{Tc}-$ HSA), left atrial myxoma was detected by both radionuclide angiocardiography and 


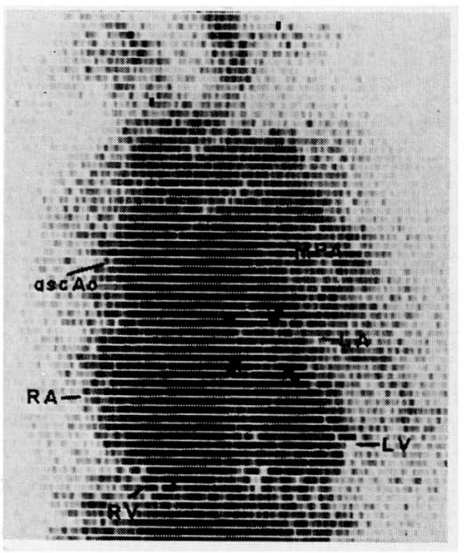

Fig. 3. Cardiac blood pool scanning : 30 minutes after injection of nuclide, there is a huge filling defect in the left atrium adjacent to the mitral valve(arrows). $\mathrm{RA}=$ right atrium, $\mathrm{RV}=$ right ventricle, $\mathrm{mPA}=$ main pulmonary artery, $\mathrm{LA}=$ left atrium, $\mathrm{LV}=$ left ventricle, asc $\mathrm{Ao}_{0}=$ ascending aorta.
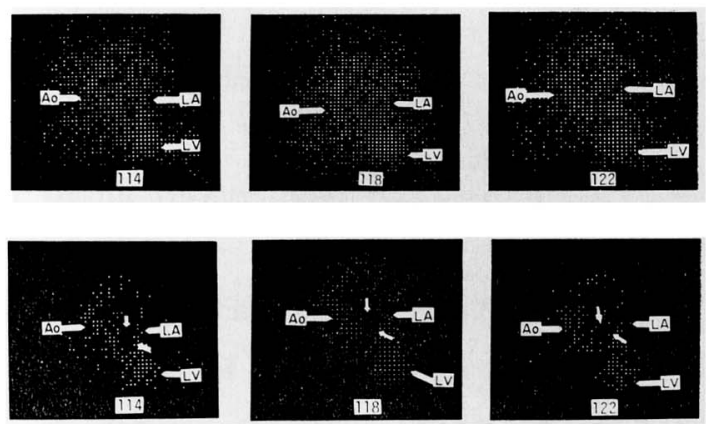

Fig. 4. Unprocessed (A) and computer processed (B) radionuclide angiocardiogram. A filling defect (see arrows) is poorly defind in the region of the left atrium in the unprocessed images on the upside. This defect (see arrows) clearly defind in the computer procssed images on the underside. Onset of exposure in frames after injection for each 0.2 second is indicated. $\mathrm{LA}=$ left atrium, $\mathrm{LV}=$ left ventricle, $\mathrm{Ao}=$ ascending aorta.

cardiac blood pool scanning (Fig. 2, 3, 4).

The findings of the cardiac catheterization are summarized in Table 1.

Left atrial myxoma was demonstrated by the angiocardiography as weell as a radionuclide angiocardiography. Angiocardiography demonstrated a huge filling defect which showed the pendullum movement between left atrium and left ventricle simultaneously to the cardiac movement (Fig. 5).

Surgery was performed on September 1, 1976, and left atrial myxoma was completely removed under the condition of hypo-thermia and cardiopulmonary bypass method. Left atrial cavity was almost entirely filled with a large pedunculated tumor arizing from the rim of fossa ovalis in the left atrial septum (Fig. 6).

Table 1. Summary of cardiac catheterization data

\begin{tabular}{|c|c|c|c|}
\hline \multirow{2}{*}{ Location } & \multicolumn{2}{|c|}{ Pressure $(\mathrm{mm} \mathrm{Hg})$} & \multirow{2}{*}{$\%$ Oxygen saturation } \\
\hline & Mean & Systolic/Diastolic & \\
\hline Superior vena cava & & & 14.9 \\
\hline Right atrium & 8 & $8.8 / 4.8$ & 14.4 \\
\hline Right ventricle & 30 & $59 /$ & 14.0 \\
\hline Main pulmpnary artery & 42 & $60 / 32$ & 14.9 \\
\hline Pulmonary capillary wedge & 35 & $\begin{array}{cccc}\mathrm{a} & \mathrm{v} & \mathrm{x} & \mathrm{y} \\
40 & 52 & 32 & 22\end{array}$ & 14.9 \\
\hline
\end{tabular}



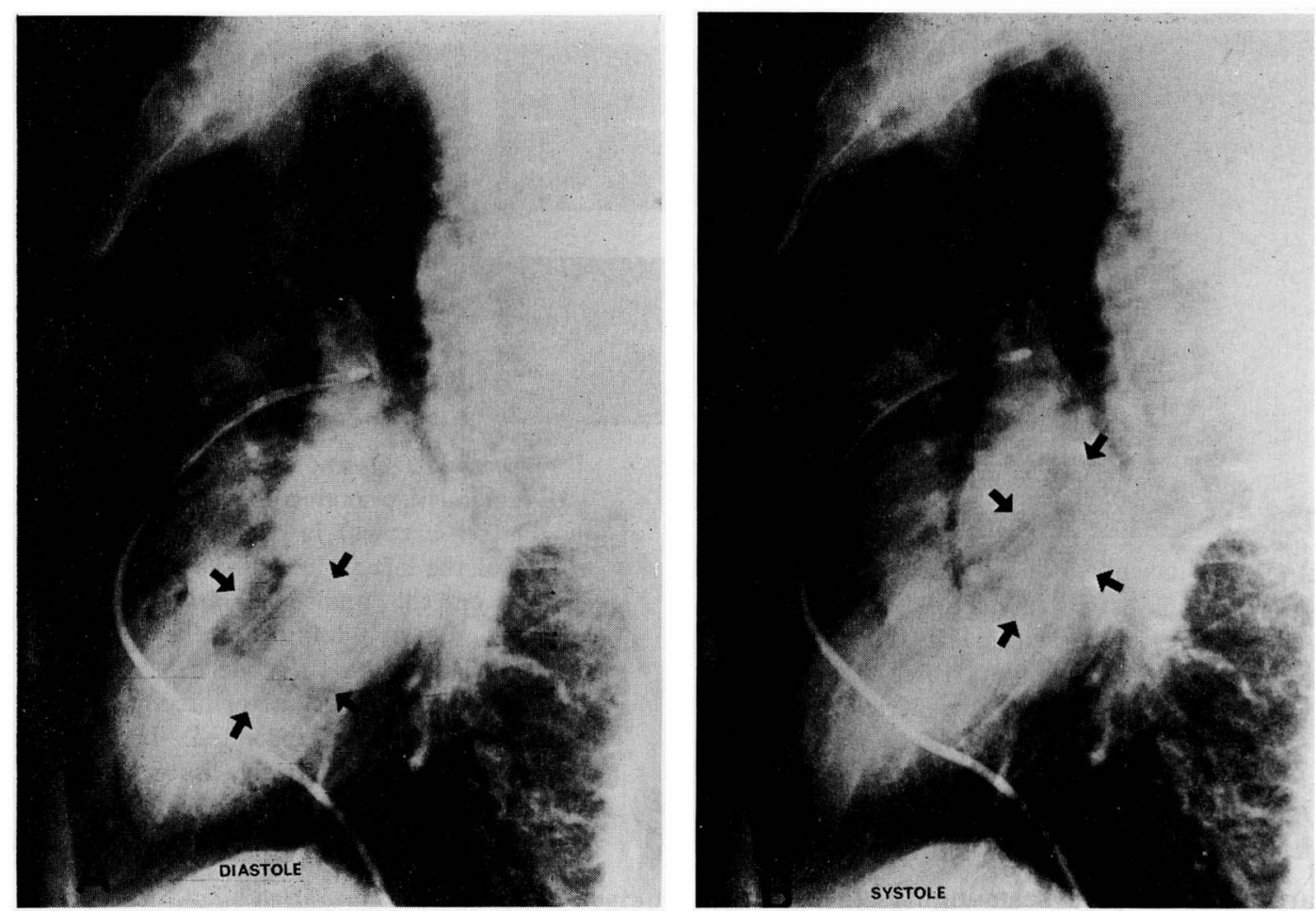

Fig. 5. Angicardiogram shows a huge filling defect which traveled from the left atrium to the left ventricle according to the cardiac movement.

A. Diastole. A large filling defect in the left ventricle is seen (arrows).

B. Systole. There is a large filling defect in the left atrium (arrows).

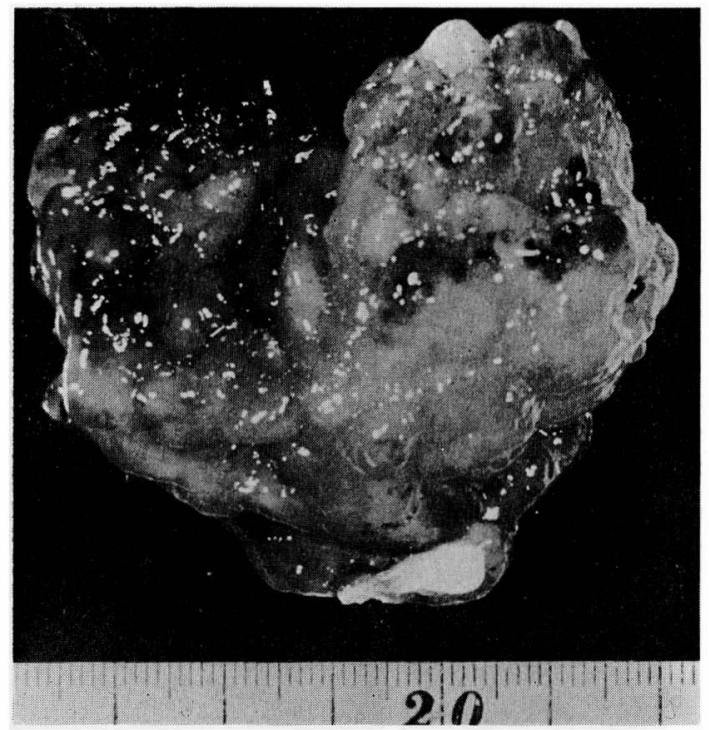

Fig. 6. Removed surgical specimen. Tumor stalk is seen in lower portion. A mass measuring approximately $5 \times 5$ $\times 3 \mathrm{~cm}$.
In addition, the mitral valve and right atrium were normal. Histologically, the gelatinous, semitransparent, light-yellowish tumor of left atrium was proved to be a typical myxoma. The postoperative course has been uncomplicated.

\section{SCINTIPHOTOGRAPHIC TECHNIQUE}

Our method of intravenous radioisotopic angiocardiography is as follows.

In order to obtain a good bolus of radionuclide, three way stopcock method is used (Fig. 7).

Teflon needle of 19 Gage caliber connected by three way stopcock to the ${ }^{99 \mathrm{~m}} \mathrm{Tc}-\mathrm{HSA}$ and saline syringe is 


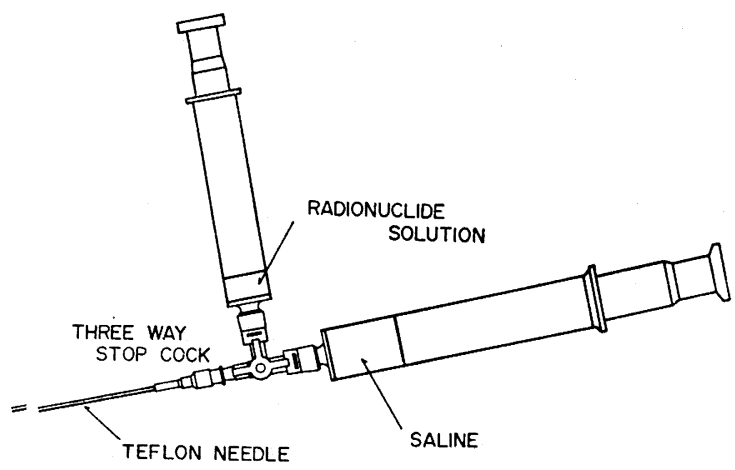

Fig. 7. Schematic representation of a simple injector system for three way stopcock method. inserted into the right femoral vein. ${ }^{99 \mathrm{~m}} \mathrm{Tc}-\mathrm{HSA}, 20 \mathrm{mCi}$ in $1 \mathrm{ml}$ saline, is rapidly injected and then the vein is flushed with $20 \mathrm{ml}$ of saline immediately. After the injection of the radionuclide in supine position, the series of cardiac scintiphotograms are taken with $30^{\circ}$ left anterior oblique projection using Toshiba Scintillation Camera GCA-202 fitted with 20,000 parallel hole high resolution low energy collimator.

The scintillation camera is connected to $32 \mathrm{~KB}$ minicomputer (TOSBAC-40C) with 4. $8 \mathrm{MB}$ disc. The counts from the camera are fed into core memory of TOSBAC-40C with list mode data acquisition format through two analog-degital converters.

Moreover, images are obtained for $300 \mathrm{msec}$ at a rate of $1 / \mathrm{sec}$ with a $35 \mathrm{~mm}$ time lapse camera equipped with a motor-driving film transport.

The cardiac blood pool scanning is started from 10 minutes after radionuclide injection using a TOSHIBA Scintillation Camera GCA-202 and a TOSHIBA dual 5 inch unit. Heart pool scan is performed with scintillation camera in various views especially with $30^{\circ}$ left anterior oblique view.

\section{RESULT}

Left anterior oblique view was best position to visualize the left atrial myxoma.

Our three way stopcock method using right femoral vein obtained a good bolus of radionuclide.

Computer handling of radionuclide angiocardiographic data was useful in the diagnosis of left atrial myxoma.

In the radionuclide angiocardiogram and heart blood pool scanning, a huge filling defect in the left atrium adjacent to mitral valve was seen (Fig. 2, 3, 4).

The position of the cardiac chambers and great vessels was normal.

The right to left shunt and left to right shunt were not seen. The results were confirmed by findings of cardiac surgery.

\section{DISCUSSION}

Since the first studies in this field were performed by Bender et al in $1963^{6}$, there 
has been steady improvement in technique ${ }^{7)-9)}$ Then, many investigators have performed radionuclide angiocardiography so that the findings under various cardiac conditions have been described ${ }^{10)-12}$ )

Right atrial myxoma has been previously demonstrated by radioisotopic procedure ${ }^{3)}$, 13)-15). Staub ${ }^{16)}$ detected metastatic tumor of the right atrium with renal cell carcinoma using radionuclide angiocardiography. It may be easier to detect tumors of right atrium since there will be the least superimposed activity from other structures along the lower right heart border.

Using radionuclide angiocardiography Steiner, et al $^{17)}$ have also recently demonstrated the presence of right ventricular metastasis from colon cancer.

Although the radionuclide angiocardiogram usually does not define anatomic detail compaired with selective contrast angiocardiography. The method has the obvious advantages of simplicity of performance, avoidance of hospitalization or cardiac catheterization, and avoidance of unfavourable pharmacologic reactions and the disturbance of cardiodynamic events. It also offers lower body radiation dose and allows frequently repeated examinations.

Before the injection of radionuclide, positioning of view must be selected. The most appreciate view to visualize the left atrium, in which there is no overlap of the four heart chambers, can be obtained with the patient in the left anterior oblique projection.

Radionuclide volume should be kept to a minimum to avoid spread of the bolus in the vein. So, the new injection system was used to keep this small volume of the material as a bolus (Fig. 7).

This system consistents of a 19 Gage teflon needle which are attached three way stopcock connecting two syringes, a syringe containing radionuclide, and the other containing saline. The syringe has a metalic lock to keep a tight connection of syringe with three way stopcock. The disporsable system is relatively simple and inexpensive.

The authors previously had been used right cubital vein, but nuclide remained in the right subclavian vein. Therfore, we have been made use right femoral vein for bolus injection of radionuclear angiocardiography. Injection from right femoral vein obtains good bolus in comparison with injection from right cubital vein.

The recording is initiated simultaneously with the injection of the radionuclide. Recording time is 30 seconds.

${ }^{99 \mathrm{~m}} \mathrm{Tc}$-HSA is the radiopharmaceutical of choice for cardiac blood-pool studies because of the superior spatial resolution afforded by the $140 \mathrm{kev}$ rays and the maintenance of 
sufficiently high blood levels during the scanning or imaging period.

Radionuclide angiocardioghy can be done with a gamma camera and a $35 \mathrm{~mm}$ time lapse camera equipped with a motor-driving film transport alone, but diagnostic information can be increased when data-handling equipment is available.

Concerning to record the cardiac images, a $35 \mathrm{~mm}$ camera with an automatic film advance mechanism may be used. However, this mechanism has a "dead-time" when the film advances (approx $600 \mathrm{msec}$ ), during this time no data can be recorded and this means that composite images of different flow phases may be missed.

Quantitative nuclear angiocardiography obtained by interfacing the camera with a digital computer allows to analyse quantitative and morphological changes. Small dedicated digital computers facilitate the analysis of the data, i, e., smoothing, uniformity, correction, image subtraction, histogram generation, etc.

Computer handling of radionuclide angiocardiographic data may be useful in the diagnosis of left atrial myxoma, Note that the filling defect is well defined in the region of the left atrium in the computer processed image, but a defect is ill defined in the unprocessed image (Fig. 4).

Recently, the diagnosis of left atrial myxoma has been greatly facilitated by echocardiography 18)19). However, it is occasionally difficult or impossible to obtain an adequate echocardiogram and the echocardiogram may not always be diagnostic tool of left atrial tumor and many false negatives heve been encountered ${ }^{20}$.

\section{SUMMARY}

The authors presented a case of a left atrial myxoma diagnosed by scintiphotographic examination and emphasize that both radionuclide angiocardiography and heart blood pool scan are simple, effective and non-invasive procedure which are very useful as a screening test in the cases that the existence of a cardiac tumor is suspected.

Computed radionuclide angiocardiography may be used in such cases as congestive heart failure, pulmonary hypertension, and either mitral or tricuspid stenois and it may be also utilized in the cases of unusual cardiomegaly in the chest rentogenograms, unusal heart murmur, arrythmia and cardiac pain is noticed independently or not.

\section{ACKNOWLEDGMENT}

The authors are indebted to Dr. Osawa of the Seirei Hospital for the cardiac surgery. We are also greatful to Mr, T. Kanno, Mr. T. Kondo, Mr. T. Fujii and Mr. S. Nobezawa for technical assistance in nuclear imaging. 


\section{REFERENCES}

1) Straus R., Merliss R. : Primary tumor of the heart. Arch Path., 39, 74-78, 1945.

2) Benjamin H. G. : Primary fibromyxoma of the heart. Arch Path., 27, 950, 1939.

3) Kriss J.P., Enright L.P., Hayden W. G., et al : Radioisotopic angiography : Wide scope of applicability in diagnosis and evaluation of therapy in diseases of the heart and great vessels. Circulation, 43, 792-808. 1971.

4) Zaret B. L., Hurley,P. J., Bertram P. : Non-invasive scintiphotographic diagnosis of left atrial myxoma. J. Nucl. Med., 13, 81-84, 1972.

5) Pohost G.M., Pastore J. O., McKusick, K, A., et al : Detection of left atrial myxoma by gated radionuclide cardiac imaging Circulaton, 55, 88-92, 1977.

6) Bender M. A., Blau M. : The autofluoroscope. Nucleonics. 21. 52-56, 1963.

7) Anger, H. O., Van Dyke, D, C., Gottschaalk, A., et al : The scintillation camera in diagnosis and research. Nucleonics, 23, 57-62, 1965.

8) Masson, D. T., Ashburn, W. L., Harbert, J.C., et al : Rapid sequential visualization of the heart and great vessels in man using a wide field Anger scintillation camera. Circulation, 39, 19-28, 1969.

9) Alazraki, N., Ashburn,W., Hagan, A., et al : Detection of left to right shunts with the scintillation camera pulmonary dilution curve. J. Nucl. Med., 13, 142-147,1972.

10) Hurley, P. J., Strauss, H.W., Wagner, H, N, Jr., et al : Nuclear angiocardiography in the cyanotic congenital heart disease. Johns Hopkins Med. J., 127, 46-54, 1970.

11) Wesselhoeft, H., Herley, P.J., Wagner, H.N.Jr., et al : Nuclear angiography in the diagnosis of congenital heart disease in infants. Circulation, 45, 77-91, 1972.

12) Matin. P., Kriss J.P. : Mitral valvular disease demonstrated by radioisotope angiocardiography. J. Nucl. Med., 11, 723-730, 1970.

13) Isley J. K. Jr., Reinhardt J. F. : Intracardiac myxoma demonstrated on a vascular scan. Am. J. Roentgen., 88, 70-72, 1962.

14) Bonte F. J., Curry T. S. III : ${ }^{98 \mathrm{~m}}$ Tc human serum albumin blood pool scan diagnosis of an intracardiac myxoma. J Nucl. Med., 8. 35-39, 1967.

15) Zitnik R. S., Giuliari E. R., Minn R. : Clinical recognition of atrial myxoma. Am. Heart J., 80, 689-700, 1970.

16) Staub R. T. : Tumor thrombus of the right atrium displayed by rapid sequence scintiphotography. J. Nucl. Med., 11, 559-560, 1970.

17) Steiner R, M., Bull, M.I., Kumpel, F., et al : The diagnosis of intracardiac metastasis of colon carcinoma by radioisotopic and roentgenographic studies. Am. J. Cardiol., 26, 300$304,1970$.

18) Kerber R.E., Kelly D.H.Jr., et al : Left atrial myxoma : demonstration by stop-action cardiac ultrasonography. Am. J. Cardiol., 34, 838-841, 1974.

19) Martinez E. C., Giles T.D., et al : Echocardiographic diagnosis of left atrial myxoma. Am. J. Cardiol. 33, 281-285, 1974.

20) Tallury V.K., DePasquale N.P : Ultrasound cardiography in the diagnosis of left atrial thrombs. Chest, 59, 501-503, 1971. 